\title{
Review
}

\section{Apathy in Parkinson's disease: Diagnosis, neuropsychological correlates, pathophysiology and treatment}

\author{
Gabriella Santangelo $^{\mathrm{a}, \mathrm{b}}$, Luigi Trojano ${ }^{\mathrm{a}, *}$, Paolo Barone ${ }^{\mathrm{b}, \mathrm{c}}$, Domenico Errico ${ }^{\mathrm{a}}$, Dario Grossi ${ }^{\mathrm{a}}$ and \\ Carmine Vitale ${ }^{b, \mathrm{~d}}$

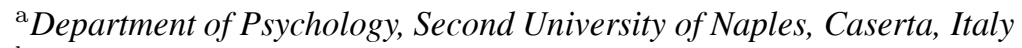 \\ b Istituto di Diagnosi e Cura "Hermitage Capodimonte", Naples, Italy \\ ${ }^{\mathrm{c}}$ Neurodegenerative Diseases Center, University of Salerno, Salerno, Italy \\ ${ }^{\mathrm{d}}$ University of Naples "Parthenope", Naples, Italy
}

\begin{abstract}
Apathy has been defined as lack of motivation. It has been traditionally considered as a symptom of psychiatric disorders, such as major depression and schizophrenia, but more recently it has been recognized as a specific neuropsychiatric syndrome associated with neurodegenerative such as Parkinson's disease (PD). As a consequence the reported prevalence of apathy in PD ranges from $13.9 \%$ to $70 \%$; the mean prevalence is 35\%. Prevalence of "pure apathy" (i.e., of apathy without comorbid depression and dementia) seems to be substantially lower, from 3 to $47.9 \%$. High levels of apathy in PD are associated with decreased daily function, specific cognitive deficits and increased stress for families. Although neuroimaging studies do not provide a unique anatomic pattern, several data suggest that the ventromedial prefrontal cortex and the basal ganglia connected through frontal-subcortical circuits, are particularly involved in the genesis of apathy. At present, there are no approved medications for the treatment of apathy in and no proof of efficacy exists for any drug in current use. Further studies and innovative pharmacologic approaches are thus needed to ameliorate our understanding and treatment of apathy in PD.
\end{abstract}

Keywords: Parkinson's disease, depression, apathy, non-motor symptoms, frontal/executive functions

\section{Introduction}

Apathy has been defined as "lack of motivation not attributable to diminished level of consciousness, cognitive impairment or emotional distress" by Marin [1, 2]. It clinically manifests as: 1) reduced goal directed behavior, 2) reduced goal directed cognition and 3) reduced emotional concomitants of goal directed behaviors. Marin provided an operational definition of each aspect of apathy: the reduced goal directed behavior was defined as lack of effort, initiative and productivity; the reduced goal directed cognition as decreased

${ }^{*}$ Corresponding author: Luigi Trojano, MD, Department of Psychology, Second University of Naples, viale Ellittico Complesso Universitario, 81100 Caserta, Italy. Tel.: +39 0823274784; E-mail: luigi.trojano@unina2.it. interests, lack of plans and goals, and lack of concern about one's own health or functional status; and finally, the reduced emotional concomitants of goal directed behaviors as flattened affect, emotional indifference and restricted responses to important life events [1].

More recently, Levy and Dubois [3] criticized Marin's definition of apathy as "lack of motivation" and proposed an alternative approach. They defined apathy as an observable and quantifiable behavioral syndrome characterized by a quantitative reduction of selfgenerated voluntary and purposeful behaviors despite the patient's contextual or physical changes. In other terms, apathy may be considered as a pathology of voluntary action or goal-directed behavior (GBD) and it may arise from alterations occurring at the level of elaboration, execution and/or control of GBD [4].

Levy and Dubois [3] proposed to divide apathetic syndromes into three subtypes on the basis of specific 
type (i.e. emotional, cognitive or behavioral) of process disrupted during the completion of GDB: 1)'emotional', 2) 'cognitive' and 3) 'auto-activation' apathy. The first subtype of apathy is related to disruption of 'emotional' processing and refers to a reduction in GDB arising from an inability to link affective and emotional signals with ongoing and forthcoming behaviors. This subtype of apathy appears as either loss of will, loss of goals or emotional blunting or as diminution of one's ability to evaluate the consequences of future actions [5]. The cognitive apathy is related to disruption of 'cognitive' processing and may be called cognitive inertia: it refers to the reduction in GDB arising from alterations of cognitive functions (e.g. executive functions) needed to elaborate the plan of actions. Finally, the third subtype of apathy is related to an 'Auto-activation' deficit: it refers to difficulties in activating thoughts or initiating the motor program needed to complete the behavior. Patients with this subtype show severe apathy, characterized by difficulties in self-initiating actions or thoughts ('mental emptiness'), contrasting with relatively spared, externally driven responses.

The apathy can appear as a symptom of psychiatric disorders, such as major depression and schizophrenia, but more recently it has been recognized as a specific neuropsychiatric syndrome arising from dysfunctions of prefrontal cortex and basal ganglia connected through fronto-subcortical circuitries [3,6]. In fact, apathy is reported in the context of several neurological disorders in which altered functioning of prefrontal cortex and/or basal ganglia occurs, such as stroke [7], Alzheimer's disease [8], Huntington's disease [9-11], or progressive supranuclear palsy [12-14]. The neurologic disease in which apathy has been most intensely investigated is Parkinson's Disease (PD). This article offers a review of clinical and neuropsychological correlates, diagnostic strategies, etiologic mechanisms and treatment of apathy in patients with PD.

\section{Prevalence of apathy in PD}

In recent years strong efforts have been made to recognize apathy in PD and to define how common it is. After the pioneering study by Starkstein et al. [15], frequency of apathy has been investigated by many authors (see Table 1). The prevalence rate of apathy in PD ranges from $13.9 \%$ to $70 \%$; the mean prevalence is $35 \%$ (see Table 1). One important factor contributing to the wide variability across studies is represent- ed by different recruitment criteria: early studies assessed prevalence including apathetic patients with depression or dementia, whereas more recently prevalence of "pure apathy" (i.e., apathy without comorbid depression and dementia) has been found to range from 3 to $47.9 \%$ (Table 1). Other possible causes of divergent data about prevalence of apathy are type of population studied (patients recruited from movement disorder units vs patients recruited from the community), and diagnostic/screening tools (self-report vs caregiver version of tools or diagnostic criteria). In detail, most prevalence studies were hospital-based and included patients recruited from outpatient neurological clinics [15,17-22,24,27,29-31,33-39]; in these studies the prevalence rate of apathy ranges from 17.2 to 70 . The few community-based prospective studies $[16,23$, $25,26,28,32]$ tend to report lower prevalence. Recently, Pedersen et al. [25] using the motivation/initiative item of UPDRS section I, found a prevalence of $37.9 \%$ (88/232 PD patients), whereas pure apathy was found in $9.1 \%$ of cases. Using more restrictive criteria (apathy subscale of Neuropsychiatric Inventory (NPI) and diagnostic consensus criteria for apathy [42] validated in PD [31]), Pedersen et al. [32] reported a prevalence of $22.9 \%$ (40 patients), in 175 non-demented, drugnaïve patients with newly diagnosed $\mathrm{PD}$, with a prevalence of "pure apathy" of $14.3 \%$. A 4 year-follow-up study [26], reported apathy in PD as a persistent behavioral feature, with an annual incidence rate of $12.3 \%$ : in other terms, occurrence of apathy increased substantially and affected more than $60 \%$ at the last follow-up. Taken together, these findings demonstrated that apathy may be considered as a non motor symptom of PD occurring since early stages of disease, and increasing in frequency as the disease progresses.

\section{Assessment and phenomenology}

According to diagnostic criteria proposed by Starkstein and Leentjens [43] apathy includes both loss of motivation and loss of emotionality. Subsequently, these diagnostic criteria have been revised by a task force commissioned by the European Alzheimer's Disease Consortium (EADC; see Table 2) [42]. In a recent validation study on a PD sample [31] EADC criteria proved to show good acceptability, internal consistency, concurrent validity, and moderate to good discriminant validity with depression. These criteria identified apathy in $17.2 \%$ of the PD sample, a rate in the lower part of abovementioned range. Therefore, EADC diag- 


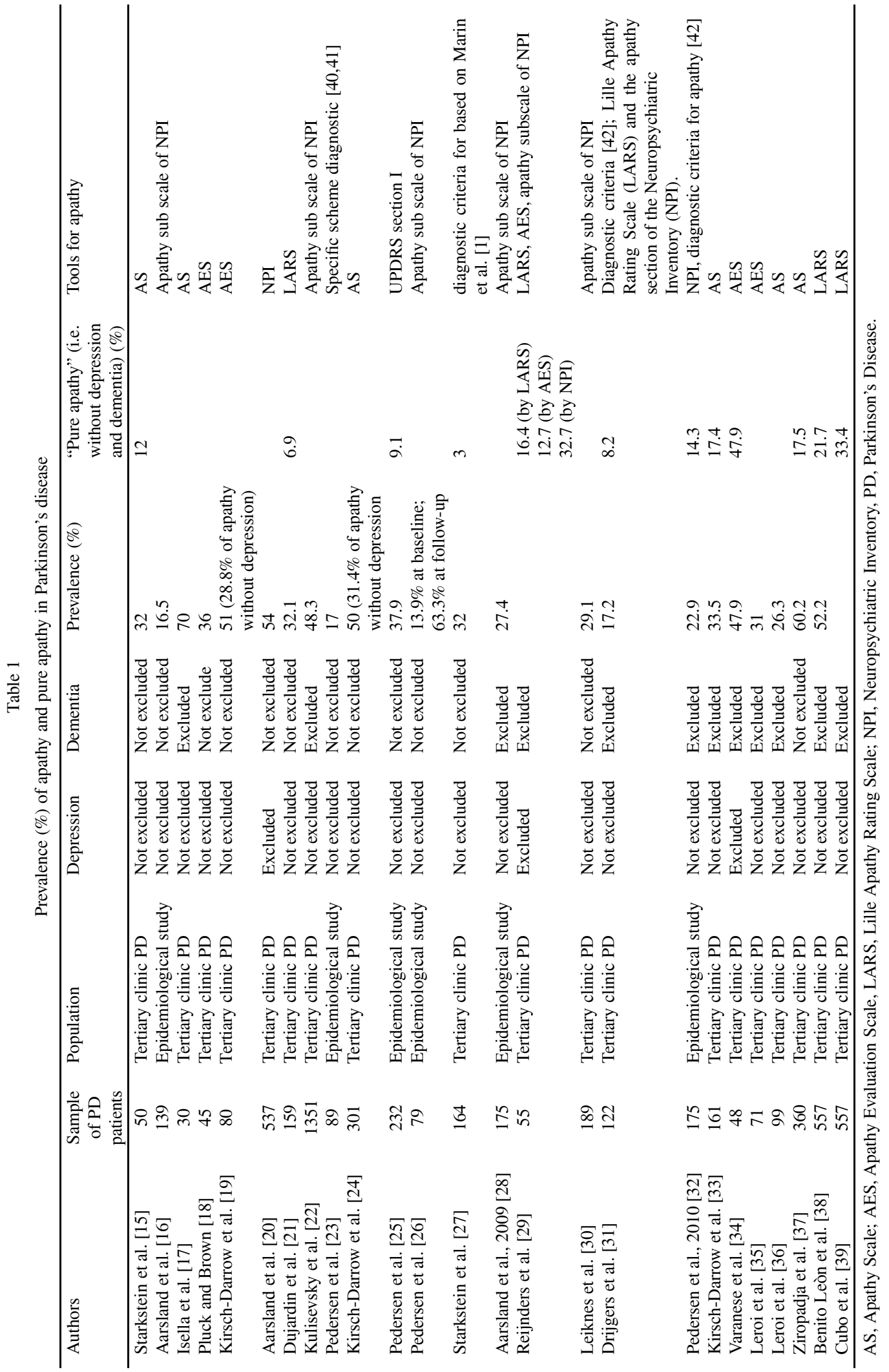


Table 2

Diagnostic criteria for apathy (adapted from [42])

For a diagnosis of apathy the patient should fulfill the criteria $A, B, C$ and $D$ :

Criterion A. Loss of or diminished motivation in comparison to the patient's previous level of functioning and which is not consistent with his age or culture. These changes in motivation may be reported by the patient himself or by the observations of others.

Criterion B. Presence of at least one symptom in at least 2 of the 3 following domains for a period of at least 4 weeks and present most of the time.

B1. Domain behaviour. Loss of, or diminished, goal-directed behaviour as evidenced by at least one of the following:

- Initiation symptom: loss of self-initiated behaviour (e.g. starting conversation, doing basic tasks of day-to-day living, seeking social activities, communicating choices);

- Responsiveness symptom: loss of environment-stimulated behaviour (e.g. responding to conversation, participating in social activities)

B2. Domain cognition. Loss of, or diminished, goal-directed cognitive activity as evidenced by at least one of the following:

- Initiation symptom: loss of spontaneous ideas and curiosity for routine and new events (i.e, challenging tasks, recent news, social opportunities, personal/family and social affairs);

- Responsiveness symptom: loss of environment-stimulated ideas and curiosity for routine and new events (i.e, in the person's residence, neighbourhood or community).

B3. Domain emotion. Loss of, or diminished, emotion as evidenced by at least one of the following:

- Initiation symptom: loss of spontaneous emotion, observed or self-reported (e.g. subjective feeling of weak or absent emotions, or observation by others of a blunted affect);

- Responsiveness symptom: loss of emotional responsiveness to positive or negative stimuli or events (for example, observer-reports of unchanging affect, or of little emotional reaction to exciting events, personal loss, serious illness, emotional-laden news)

Criterion $C$. These symptoms (A and B) cause clinically significant impairment in personal, social, occupational, or other important areas of functioning.

Criterion D. The symptoms (A and B) are not exclusively explained or due to physical disabilities (e.g. blindness and loss of hearing), to motor disabilities, to diminished level of consciousness or to the direct physiological effects of a substance (e.g. drug of abuse, a medication.

nostic criteria, that appear to be well suited for clinical practice and research, seem to be relatively conservative if compared to cut-off scores on currently available apathy rating scales [31].

In common clinical practice and research several questionnaires are now available for diagnosis of apathy in PD patients, and some of them encompass different versions to be compiled by clinician, by informant, or by patient as a self-rating scale. Presence and severity of apathy are often assessed by means of the apathy subscale included in NPI [16,20,22,26,28-32]. In most studies, however, apathy has been identified by means of self-report questionnaires, such as the Apathy Evaluation Scale (AES) [44], and its 14-item abbreviated form, the Apathy Scale (AS) [15,17-19,24,29,33-37], easier to be administered to PD patients. Using some items of the Apathy Scale and the standardized criteria adapted from Marin [1], an algorithm to diagnose apathy has been developed for Alzheimer's disease [45], and validated for PD [27].

Recently, a task force commissioned by the Movement Disorders Society (MDS) to compare several apathy and anhedonia scales in PD, concluded that item 4 of the Unified Parkinson Disease Rating Scale is useful only for "crude screening purposes", whereas the AS is "recommended" for the assessment of apathy in PD [46]. However, since the AS yields only a global score and thus provides little information about profiles of apathy, recently, a new tool has been developed, the Lille Apathy Rating Scale (LARS) [47], whose French and English versions have been specifically validated in PD patients $[47,48]$. The LARS is a semi-structured interview assessing four distinct dimensions of apathy: intellectual curiosity (IC), emotion (E), action initiation (AI), and self-awareness (SA). The LARS seems to provide information about different clinical manifestations (i.e., cognitive, behavioral, affective) of apathy [47] and represents a potentially useful instrument to characterize apathy in PD. Dujardin et al. [21], using the LARS, found that among its four dimensions (IC, E, AI and SA) AI and IC dimensions contributed strongly to severity of apathy in PD. Subsequently, using EADC diagnostic criteria [42], Drijngers et al. [31] found that reduced goal-directed behavior followed by reduced goal-directed cognition are the most frequently reported domains in apathetic PD patients; reduced spontaneous emotion seems to occur most often in combination with one or both of the other two domains, and its presence may signal more severe levels of apathy.

Since demented or severely apathetic PD patients may be unaware of their condition, use of self-report versions of available scales may result in underestimation of the symptom; for this reason, it is very important to debrief patients' caregivers, who usually are a reliable source of information. A specific informant-based version is included in the LARS (the LARS-i) [49]. Ideally, assessment of apathy in PD should include information collected from both the patient and the carer, and also take into account systematic observation from physician's perspective, possibly guided by a for- 
malized inventory such as that suggested in a recent study [50].

\section{Relationships between apathy and depression}

Particular mention should be made of the relationships between apathy and depression, since apathy has been traditionally considered as an aspect of depression. The overlap between apathy and depression can cause substantial difficulties in identifying and distinguishing apathetic patients from depressed patients in PD [51,52]. Although most studies found an association between apathy and depression in PD patients [25,26, $32,34,37,38]$, and between apathy and anhedonia [18, $52,53]$, others showed that apathy may occur independently of depression in PD [17-19,33,39,52]. Apathetic PD patients can be misdiagnosed as depressed, and consequently treated with inadequate drugs [52]; therefore, although difficult, recognizing apathy and differentiating it from depression is important also in view of possible differentiated treatment strategies (see below).

Recently, Kirsch-Darrow et al. [33] confirmed that apathy and depression can dissociate in PD, and are characterized by different features: depression includes sadness and negative thoughts about the self, while diagnosis of apathy rests on lack of initiation and lack of effort, but not on negative self or event appraisal. In this perspective, Kirsch-Darrow et al. [33] analysed items from the Beck Depression Inventory (BDI-II) and the AS, and found that they can be combined to obtain four separate subscales ("pure" apathy, "pure" depression, overlapping symptoms of loss of interest and pleasure, and somatic symptoms) to differentiate specific symptoms related to apathy or depression. Moreover, in a recent longitudinal study, Zahodne et al. [54] found that apathy and depression show a different progression over time: apathy worsened following a linear evolution, whereas depressive symptoms tended to show a fluctuating course, with improvement and worsening over time. These findings further supported the dissociation between apathy and depression in PD.

\section{Clinical and cognitive correlates of apathy in PD}

Few studies investigated demographic and specific clinical correlates of apathy in PD. As for association between gender and apathy, some studies reported that apathy is more frequent in male than in female PD patients $[17,21,32]$ but such findings were not confirmed
Table 3

Studies reporting an association of apathy with demographic and clinical aspects of Parkinson's disease

\begin{tabular}{ll}
\hline Clinical factor & Authors \\
\hline Age & Benito-Leon et al. [38] \\
& Ziropadja et al. [37] \\
& Pedersen et al. [25] \\
Education & Cubo et al. [39] \\
& Benito-Leon et al. [38] \\
& Pedersen et al. [25] \\
Disease duration & Ziropadja et al. [37] \\
Severity of motor symptoms & Cubo et al. [39] \\
& Benito-Leon et al. [38] \\
& Pedersen et al. [32] \\
& Dujardin et al. [55] \\
& Pedersen et al. [25] \\
Axial impairment & Ziropadja et al. [37] \\
Right predominant PD motor laterality & Cubo et al. [39] \\
L-dopa dosage & Ziropadja et al. [37] \\
& Pedersen et al. [25] \\
\hline
\end{tabular}

L-dopa, Levodopa; PD, Parkinson's Disease.

by other studies $[37,55]$. The association between apathy and male gender might indirectly support the possible role of testosterone levels in pathophysiology of apathy in male parkinsonians [56] but could also suggest that female caregivers pay attention and tend to report negative affective symptoms more frequently than male caregivers [32].

Apathetic PD patients are often less educated and older, use higher daily levodopa doses, have longer disease duration and more severe parkinsonism than nonapathetic patients [21,25,32,37-39] (see Table 3), although some divergent findings have been reported [17, $32,33]$. While the association of poor education and apathy remains to be investigated [39], the correlation between apathy and clinical aspects of PD does not necessarily entails that apathy and motor symptoms share the same neural bases, but might suggest that degenerative processes underlying the two kinds of symptoms develop in parallel as the disease progresses. Actually, several studies have reported an association between apathy and motor symptoms, but many others have underlined that apathy can manifest in early stages of the disease, before development of relevant motor disability [32]. Moreover, as it will be discussed below, some lines of evidence suggest that apathy seems to be related to alteration of non-dopaminergic circuits.

Recently, Cubo et al. [39] found that patients living in a rural environment, with lower comorbidity and motor impairment, higher education background, and left predominant PD motor laterality were at lower risk of suffering from apathy. 
In a 4-year prospective population-based longitudinal cohort study, Pedersen et al. [26] reported that dementia at baseline and a more rapid decline in speech and axial impairment during follow-up were independent risk factors for incident apathy. Moreover, Dujardin et al. [55] found that dementia was more frequent and severe in apathetic PD patients than in nonapathetic PD patients, and that apathy may be a predictive factor for cognitive decline over time in nondemented, non-depressed PD patients. According to the authors [55], the association between apathy and cognitive decline might be ascribed to an alteration of nondopaminergic circuits, mainly of cholinergic circuits originating in the basal forebrain nuclei - the main source of cholinergic projections to the cortex- both in $\mathrm{PD}$ [57] and in AD and related dementias [58,59].

The relationship between specific cognitive deficits and apathy has received increasing attention. Studies using brief cognitive screening tests (Mini Mental State Examination or Mattis Dementia Rating Scale) [15$18,21,25,32,37]$ found an association between apathy and cognitive impairment or dementia [16,18,25,32]. In other studies, specific tests have been used to assess the following neuropsychological domains: frontal lobe functions, memory and visuospatial skills (Table 4) [15, $17,18,32,34,60]$.

A consistent finding was that apathetic patients performed worse than non apathetic patients on specific frontal tests tapping spatial planning and cognitive flexibility $[15,17,18,32,34,60]$. However, most of these studies investigated neuropsychological correlates of apathy in PD without excluding PD patients with dementia and/or depression. Only two studies considered dementia and depression as exclusion criteria and found that patients with "pure apathy" performed worse than non apathetic PD patients on frontal tasks, thus suggesting a strong association between "pure apathy" and frontal dysfunctions [34,55]. However, this issue should be further investigated.

In the domain of memory, some studies did not find significant differences between apathetic and nonapathetic PD patients on short-term and long-term memory tasks $[17,32,60]$. On the contrary, three studies revealed that apathetic patients performed worse than non-apathetic patients on the memory subtest of the Cambridge Cognitive Examination (CAMCOG) [18], on Grober and Buschke 16-item recall test [55], and on paired associative learning test [15]. However, in these studies patients with dementia or depression were not excluded. Only one recent study [34] evidenced that patients with "pure apathy" had more difficulties on recall and recognition tasks of the California Verbal Learning Test II; the authors interpreted this impairment as due to poor strategy implementation at the encoding and the recall stages rather than a primary memory disorder [34].

Few studies explored visuospatial functions in PD patients with apathy and reported divergent findings [18,32,60]. Pedersen et al. [32] using a silhouette recognition task and Pluck and Brown [18] using the praxis subtest of CAMCOG found an association between impaired visuoperceptive and visuoconstructive functions and apathy in PD, whereas one study did not find this relationship [60].

The inconsistency in findings about association between apathy and cognitive deficits (memory and frontal dysfunctions) may be accounted for by methodological differences: these studies used a number of different measures to assess apathy or cognitive functions and different inclusion and exclusion criteria. However, most studies converge in highlighting that apathy, and particularly "pure apathy", is particularly related to dysexecutive dysfunctions, and these observations are consistent with the possible neural underpinnings of apathy (see below).

\section{Impact of apathy on patients' and caregivers' quality of life in PD}

It is well-established that PD patients experience progressive loss of ability to perform activities of daily living due to their motor disturbances, but in recent years some studies have demonstrated that apathy per se is associated with a decrease in functional autonomy [17, 32,61].

Increasing evidence is also accumulating about the impact of apathy on quality of life (QoL) in PD patients. It is now becoming clear that apathy contributes to reduce QoL in both early and advanced stages of the disease [38,61-63]. For example, in the PRIAMO study [62], a multicenter Italian survey involving 1072 PD patients, apathy was the symptom most often associated with poor QoL; however, a limitation of that study was that apathy was only assessed using few questions with dichotomous (yes/no) answers, without using a validated instrument. One recent study, using the LARS for diagnosis of apathy, found that apathy is one of the major clinical determinants of reduced QoL in recently diagnosed PD patients [38]. These results suggest that apathy may be a marker of poor QoL in 


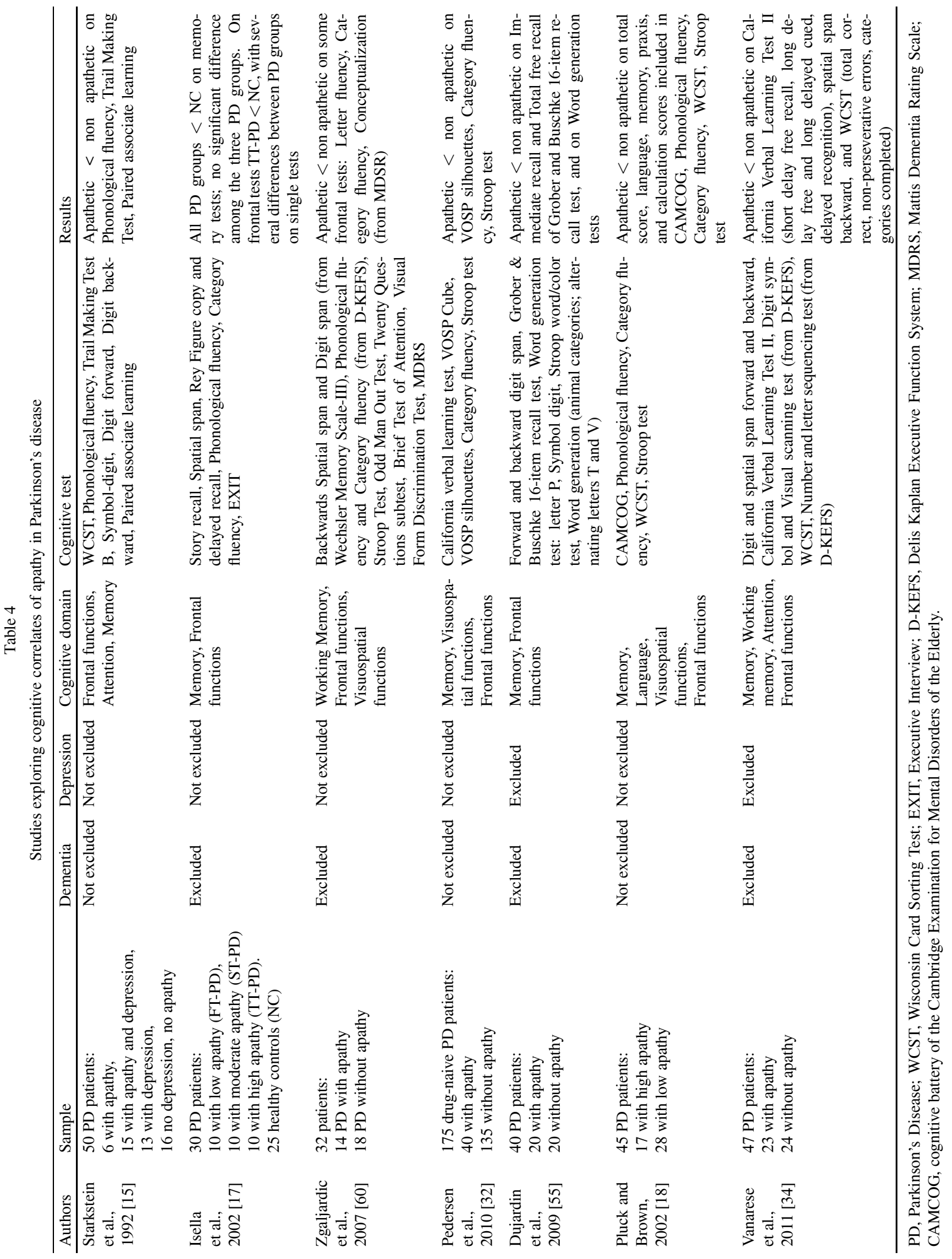


Table 5

Results of neuroimaging studies on apathy in Parkinson's disease

\begin{tabular}{|c|c|c|c|c|}
\hline Authors & Methods & \# of Subjects & Apathy & Results \\
\hline $\begin{array}{l}\text { Isella et } \\
\text { al. [17] }\end{array}$ & MRI & 26 PD patients & Self-rated AS & $\begin{array}{l}\text { No correlation between any specific measure of frontotemporal } \\
\text { atrophy and severity of apathy }\end{array}$ \\
\hline $\begin{array}{l}\text { Remy et } \\
\text { al. [66] }\end{array}$ & PET & $\begin{array}{l}8 \mathrm{PD} \text { patients with and } 12 \mathrm{PD} \\
\text { patients without episodes of } \\
\text { major depression based on } \\
\text { DSM-IV criteria. }\end{array}$ & AES & $\begin{array}{l}\text { Apathy was inversely correlated with }{ }^{11} \text { C-RTI- } 32 \text { binding } \\
\text { (dopamine and noradrenaline) in the ventral striatum bilaterally }\end{array}$ \\
\hline $\begin{array}{l}\text { Le Jeune } \\
\text { et al. [67] }\end{array}$ & PET & $\begin{array}{l}12 \text { PD patients after deep } \\
\text { brain stimulation (DBS) of } \\
\text { the subthalamic nucleus }\end{array}$ & $\begin{array}{l}\text { Clinical version } \\
\text { of AES }\end{array}$ & $\begin{array}{l}\text { Increase of metabolism was correlated with modified apathy } \\
\text { scores in the right frontal lobe, middle } \\
\text { Gyrus (BA 10) and inferior gyrus (BA } 45 \text { and 46). temporal } \\
\text { lobe (fusiform gyrus, BA 20), and postcentral gyrus (BA 43) } \\
\text { (Fig. 2). Decrease of metabolism was correlated with modified } \\
\text { apathy scores in the bilateral cingulated gyrus (BA 31) and left } \\
\text { middle frontal gyrus (BA 9). }\end{array}$ \\
\hline $\begin{array}{l}\text { Reijnders } \\
\text { et al. [29] }\end{array}$ & 3 T MRI & 55 PD patients & $\begin{array}{l}\text { Informant-AES- } \\
\text { I, LARS, apathy } \\
\text { subtest of NPI }\end{array}$ & $\begin{array}{l}\text { Apathy scores were found to be correlated with low GM density } \\
\text { in the right posterior cingulate (PC) gyrus, and the bilateral } \\
\text { inferior frontal gyrus } \\
\text { High apathy scores were correlated with low gray matter den- } \\
\text { sity values in a number of cortical brain areas: the bilateral } \\
\text { precentral gyrus (BA } 4,6 \text { ), the bilateral inferior parietal gyrus } \\
\text { (BA 40), the bilateral inferior frontal gyrus (BA 44, 47), the } \\
\text { bilateral insula (BA 13), the right (posterior) cingulate gyrus } \\
\text { (BA 24, 30,31), and the right precuneus (BA 31). }\end{array}$ \\
\hline $\begin{array}{l}\text { Skidmore } \\
\text { et al. [65] }\end{array}$ & resting fMRI & 15 PD patients & $\begin{array}{l}\text { Caregiver and } \\
\text { self-report } \\
\text { LARS }\end{array}$ & $\begin{array}{l}\text { Increasing severity of apathy is associated with increased nor- } \\
\text { malized ALFF signal in the right middle orbital gyrus and in the } \\
\text { subgenual cingulated bilaterally and with decreased activity in } \\
\text { the left supplementay motor region, left inferior parietal lobule } \\
\text { and in the left fusiform gyrus. } \\
\text { Decreased ALFF activity in the Supplementary Motor Cortex } \\
\text { and increased activity in the Right Orbitofrontal Cortex, and } \\
\text { the Right Middle Frontal Gyrus predicts apathy score. }\end{array}$ \\
\hline $\begin{array}{l}\text { Robert et } \\
\text { al. [68] }\end{array}$ & PET & $\begin{array}{l}45 \text { PD patients without } \\
\text { dementia or depression }\end{array}$ & AES & $\begin{array}{l}\text { Positive correlation between apathy cerebral metabolism in the } \\
\text { right inferior frontal gyrus (Brodmann area [BA] [47]), right } \\
\text { middle frontal gyrus (BA 10), right cuneus (BA 18), and right } \\
\text { anterior insula (BA 13). Negative correlation was found be- } \\
\text { tween apathy and cerebellar metabolism. }\end{array}$ \\
\hline
\end{tabular}

fMRI, functional Magnetic Resonance; PET, Positron Emission Tomography; PD, Parkinson's Disease; AS, Apathy Scale; AES, Apathy Evaluation Scale; LARS, Lille Apathy Rating Scale; NPI, Neuropsychiatric Inventory.

recently diagnosed PD and might affect all spheres of patients' subjective health status.

Very recent studies also demonstrated that apathy is associated with increased caregiver burden in PD patients with and without dementia [30,35]. Caregiver burden refers to the physical, mental and socioeconomic problems that arise from caring for an individual affected by a chronic and disabling disease, such as PD [64]. Leiknes et al. [30] found that apathy is the non-motor symptom most commonly associated with caregiver distress in PD.

\section{Neuro-anatomical and functional correlates of apathy in PD}

The neurobiology of apathy in PD is complex and probably involves several different pathophysiological mechanisms, depending on the stage of disease and comorbid neuropsychiatric conditions. Apathy has been associated with deficits of the prefrontal-basal ganglia circuits [3]. Despite the fact that apathy is among the major neuropsychiatric features of PD, only limited MRI and functional studies explored neural correlates of apathy in PD (Table 5).

Isella et al. [17] examined a consecutive series of patients affected by idiopathic PD using an extensive neuropsychological battery and Marin's Apathy Scale; PD patients underwent MRI scan, followed by linear measurement of several frontotemporal structures. Approximately $45 \%$ of the PD sample showed apathy; no specific pattern of frontal and/or temporal atrophy was found to be associated with apathy. This discrepancy between the neuropsychological and the neuroradiological findings might be due to the lack of sensitivity and/or accuracy of the morphometric linear tech- 
nique. In fact, a MRI voxel-based morphometry (VBM) study [29], found that in PD patients high apathy scores were correlated with low gray matter density values in several cortical brain areas, such as bilateral precentral gyrus, bilateral inferior parietal gyrus, bilateral inferior frontal gyrus, bilateral insula, right posterior cingulate gyrus, and right precuneus. Based on the involvement of the cingulate and premotor cortices the authors suggested that "autoactivation" deficits could be associated with apathy in PD, in line with the results of earlier studies addressing apathy in patients with Alzheimer's disease or depressive disorder [29].

Skidmore et al. [65] examined the relationship between apathy, depression, severity of motor symptoms and amplitude of low frequency fluctuation (ALFF) in a resting state fMRI paradigm. Apathy score on caregiver version of the LARS was best predicted by ALFF signal in the left supplementary motor cortex, the right orbitofrontal cortex, and the right middle frontal cortex. On this basis, the authors suggested that apathy may be either an "active-avoidant" syndrome due to hyperactivity of the right orbitofrontal lobe, or a purely "amotivational" syndrome due to reduced activity of the supplementary motor cortex; these two factors may combine to varying degrees and explain the wide variability of conditions that cause apathy [65].

A PET study by Remy et al. showed that in PD patients with and without major depression, high apathy scores were associated with decreased C-RTI-32 binding (dopamine and noradrenaline) in ventral striatum bilaterally [66]. In another PET study [67] apathy scores after deep brain stimulation of the subthalamic nucleus were found to be significantly correlated with decreased glucose metabolism in the left middle frontal gyrus and in the bilateral posterior cingulated gyrus a region with a critical role in the regulation of negative emotions through the encoding of emotional significance of the stimuli. Moreover, increased apathy scores significantly correlated with increased metabolic activity in the right frontal lobe, postcentral gyrus, and temporal lobe. Very recently, the same authors also found that metabolism within bilateral posterior lobe of the cerebellum inversely correlated with the AES score, in a cohort of 45 non-demented and non-depressed PD patients. These results support the view of a topographic segmentation of the cerebellum, with some structures implicated in motivation and behavioral regulation [68].

It is worth mentioning that two of the above neurofunctional studies $[65,68]$ supported the view that the neural bases of apathy can be distinguished from neural correlates of depression in PD patients, thus reinforcing the idea that the two disorders are dissociable.

In conclusion, although apathy has been explained in terms of dysfunction of segregated frontal-subcortical loops [3], results of structural and functional studies failed to provide a unique anatomical pattern underlying apathy in PD and should be reinterpreted in a model which privileges lack of segregation between these circuits especially those linking the ventromedial prefrontal cortex to related regions in the basal ganglia.

\section{Treatment of apathy in PD}

At present, there are no approved drugs for treatment of apathy and no proof of efficacy exists for any drug in current use. Pharmacologic agents most frequently administered to apathetic patients include dopaminergic drugs, acetylcholinesterase inhibitors, atypical antipsychotics and psychostimulants. Few studies have assessed efficacy of psychotropic treatment for apathy in PD, and no randomized controlled trials have been conducted [69].

Treatment of coexisting apathy with dopaminergic drugs or the glutamatergic antagonist amantadine has been reported with some clinical benefits, but no randomized and well-controlled study confirmed these observations [69-72]. Whether L-dopa treatment may improve apathy remains unclear. Czernecki et al. [73] investigated motivation and sensitivity to reinforcement in 23 non-demented and non-depressed PD patients and found that L-dopa treatment may improve the subjective evaluation of motivation in apathetic PD patients. The same authors [71] reported long-term (6 months) efficacy of the dopamine agonist ropinirole (1-18 mg/day) in an open-label study that included 8 PD patients who developed apathy after withdrawal from dopaminergic treatment following deep brain stimulation (DBS) of the subthalamic nucleus (STNDBS).

A recent meta-analysis on randomized, double-blind, placebo-controlled trials of pramipexole [74] found 7 trials $(N=1296)$ in which part I of the UPDRS was employed as a secondary outcome measure: results of this meta-analysis suggested that pramipexole had a beneficial effect on mood and motivational symptoms in PD patients who did not have major depressive disorder [74].

Further evidence suggesting that dopaminergic pathways contribute to pathogenesis of apathy derived from studies on DBS in PD patients. STN-DBS can induce 
or exacerbate apathy in some parkinsonian patients [69, 75-77]: in some patients apathy increased in severity and frequency, probably due to discontinuation of dopaminergic treatment after surgery, whereas in other patients no changes or even improvement were observed after surgery [77]. Stimulation of the associative and limbic region of the subthalamic nucleus and related structures has been proposed to be related to onset or worsening of apathy after surgery $[77,78]$.

The reported association between apathy and cognitive symptoms but not motor deficits [21] might suggest that non-dopaminergic circuits are related to mechanism of apathy in PD. Drugs known to affect one or more non-dopaminergic transmitter systems have also be evaluated, alone or in combination, within or across comorbidities. A randomized controlled trial exploring efficacy of atomoxetine, a selective norepinephrine reuptake inhibitor, for treatment of clinically significant depressive symptoms in PD patients, with apathy as a secondary outcome measure, showed no benefit for either depression or apathy [79]. An open, noncomparative clinical study to assess efficacy and safety of tricyclic tianeptine, including 18 depressed PD patients (assessed on the Hamilton and Beck scales), showed no efficacy on motivation deficits and apathy [80]. A significant improvement of apathy was reported in a PD patient after treatment with $10 \mathrm{mg}$ of methylphenidate, a stimulant drug chemically related to amphetamine that inhibits dopamine uptake and activates the brainstem arousal system and cerebral cortex [81].

Finally, two ongoing clinical trials are evaluating efficacy of acetylcholinesterase and MAO-B inhibitors on apathetic symptoms in PD patients. The first is a randomized, double-blind, placebo-controlled, parallelgroup, multicenter trial to evaluate efficacy and acceptability of a 6-month treatment with rivastigmine on apathy in 60 PD non-demented patients [ClinicalTrials.gov identifier: NCT00767091; http://clinicaltrials. gov/ct2/show/NCT00767091]. This study has been completed but results have not yet been provided and published. The second ongoing randomised placebocontrolled trial evaluates efficacy of rasagiline in patients with Parkinson's disease and symptoms of apathy [ClinicalTrials.gov identifier: NCT00755027; http: //clinicaltrials.gov/ct2/show/NCT00755027]. The primary outcome measure will be the mean change from baseline to study endpoint (week 12) in apathy scores as measured by the LARS and the Apathy Scale.

\section{Conclusions}

The large number of studies reviewed here witnesses that apathy cannot be considered anymore as a component of other psychiatric disturbances but is per se a cardinal non-motor features of PD, with a strong impact on patients' and their carers' wellbeing. Apathy can manifest since early stages of the disease and tends to increase its prevalence and severity in later stages, although this does not imply a direct link with progression of motor disturbances. The studies reviewed here provided divergent findings on many aspects, but the increasing awareness that apathy can manifest as a "pure" disorder has led researchers to select for their studies patients without depression or general cognitive impairment.

The most recent studies on "pure" apathy offered some convergent data about the relationships of apathy with cognitive dysexecutive deficits, in line with the hypothesis that specific neural underpinnings of apathy have to be searched for in a dysfunction of prefrontal cortex, and of the related cortico-subcortical circuits. However, available brain structural and metabolic studies failed to provide a clear pattern of neural correlates of apathy in PD. Likely, a broader approach, including for instance assessment of patients' personality traits, living environment, quality of supports and other relevant possible contributing motor and psychiatric factors, will improve understanding of apathy in PD.

Despite apathy is increasingly recognized as a source of significant disability in PD patients, no adequate trials have been conducted and no medication has been approved for this disorder. Additional studies are thus needed to address the contribute of the dopaminergic and non-dopaminergic systems in the pathogenesis of apathy in PD and to ameliorate treatment strategies.

\section{References}

[1] Marin RS. Apathy: a neuropsychiatric syndrome. J Neuropsychiatry Clin Neurosci. 1991; 3(3): 243-254.

[2] Marin RS. Apathy: concept, syndrome, neural mechanisms, and treatment. Semin Clin Neuropsychiatry. 1996; 1(4): 304314.

[3] Levy R, Dubois B. Apathy and the functional anatomy of the prefrontal cortex-basal ganglia circuits. Cereb Cortex. 2006; 16(7): 916-928.

[4] Brown RG, Pluck G. Negative symptoms: the 'pathology' of motivation and goal-directed behaviour. Trends Neurosci. 2000; 23(9): 412-417.

[5] Eslinger PJ, Damasio AR. Severe disturbance of higher cognition after bilateral frontal lobe ablation: patient EVR. Neurology. 1985; 35(12): 1731-1741. 
[6] Levy R, Czernecki V. Apathy and the basal ganglia. J Neurol. 2006; 253(Suppl 7): VII54-61.

[7] Jorge RE, Starkstein SE, Robinson RG. Apathy following stroke. Can J Psychiatry. 2010; 55(6): 350-354.

[8] Robert PH, Mulin E, Malléa P, David R. Apathy diagnosis, assessment, and treatment in Alzheimer's disease. CNS Neurosci Ther. 2010; 16(5): 263-271.

[9] Craufurd D, Thompson JC, Snowden JS. Behavioral changes in Huntington Disease. Neuropsychiatry Neuropsychol Behav Neurol. 2001; 14(4): 219-226.

[10] Hamilton JM, Salmon DP, Corey-Bloom J, Gamst A, Paulsen JS, Jerkins S, Jacobson MW, Peavy G. Behavioural abnormalities contribute to functional decline in Huntington's disease. J Neurol Neurosurg Psychiatry. 2003; 74(1): 120-122.

[11] Thompson JC, Snowden JS, Craufurd D, Neary D. Behavior in Huntington's disease: dissociating cognition-based and moodbased changes. J Neuropsychiatry Clin Neurosci. 2002; 14(1): 37-43.

[12] Aarsland D, Litvan I, Larsen JP. Neuropsychiatric symptoms of patients with progressive supranuclear palsy and Parkinson's disease. J Neuropsychiatry Clin Neurosci. 2001; 13(1): 42-49.

[13] Litvan I, Hauw JJ, Bartko JJ, Lantos PL, Daniel SE, Horoupian DS, McKee A, Dickson D, Bancher C, Tabaton M, Jellinger $\mathrm{K}$, Anderson DW. Validity and reliability of the preliminary NINDS neuropathologic criteria for progressive supranuclear palsy and related disorders. J Neuropathol Exp Neurol. 1996; 55(1): 97-105.

[14] Litvan I, Paulsen JS, Mega MS, Cummings JL. Neuropsychiatric assessment of patients with hyperkinetic and hypokinetic movement disorders. Arch Neurol. 1998; 55(10): 1313-1319.

[15] Starkstein SE, Mayberg HS, Preziosi TJ, Andrezejewski P, Leiguarda R, Robinson RG. Reliability, validity, and clinical correlates of apathy in Parkinson's disease. J Neuropsychiatry Clin Neurosci. 1992; 4(2): 134-139.

[16] Aarsland D, Larsen JP, Lim NG, Janvin C, Karlsen K, Tandberg E, Cummings JL. Range of neuropsychiatric disturbances in patients with Parkinson's disease. J Neurol Neurosurg Psychiatry. 1999; 67(4): 492-496.

[17] Isella V, Melzi P, Grimaldi M, Iurlaro S, Piolti R, Ferrarese C, Frattola L, Appollonio I. Clinical, neuropsychological, and morphometric correlates of apathy in Parkinson's disease. Mov Disord. 2002; 17(2): 366-371.

[18] Pluck GC, Brown RG. Apathy in Parkinson's disease. J Neurol Neurosurg Psychiatry. 2002; 73(6): 636-642.

[19] Kirsch-Darrow L, Fernandez HH, Marsiske M, Okun MS, Bowers D. Dissociating apathy and depression in Parkinson disease. Neurology. 2006; 67(1): 33-38.

[20] Aarsland D, Brønnick K, Ehrt U, De Deyn PP, Tekin S, Emre M, Cummings JL. Neuropsychiatric symptoms in patients with Parkinson's disease and dementia: frequency, profile and associated care giver stress. J Neurol Neurosurg Psychiatry. 2007; 78(1): 36-42.

[21] Dujardin K, Sockeel P, Devos D, Delliaux M, Krystkowiak P, Destée A, Defebvre L. Characteristics of apathy in Parkinson's disease. Mov Disord. 2007; 22(6): 778-784.

[22] Kulisevsky J, Pagonabarraga J, Pascual-Sedano B, GarcíaSánchez C, Gironell A; Trapecio Group Study. Prevalence and correlates of neuropsychiatric symptoms in Parkinson's disease without dementia. Mov Disord. 2008; 23(13): 18891896.

[23] Pedersen KF, Larsen JP, Aarsland D. Validation of the Unified Parkinson's Disease Rating Scale (UPDRS) section I as a screening and diagnostic instrument for apathy in patients with Parkinson's disease. Parkinsonism Relat Disord. 2008; 14(3): 183-186.

24] Kirsch-Darrow L, Zahodne LB, Hass C, Mikos A, Okun MS, Fernandez HH, Bowers D. How cautious should we be when assessing apathy with the Unified Parkinson's Disease Rating Scale? Mov Disord. 2009; 24(5): 684-688.

[25] Pedersen KF, Larsen JP, Alves G, Aarsland D. Prevalence and clinical correlates of apathy in Parkinson's disease: a community-based study. Parkinsonism Relat Disord. 2009; 15(4): 295-299.

[26] Pedersen KF, Alves G, Aarsland D, Larsen JP. Occurrence and risk factors for apathy in Parkinson disease: a 4-year prospective longitudinal study. J Neurol Neurosurg Psychiatry. 2009; 80(11): 1279-1282.

[27] Starkstein SE, Merello M, Jorge R, Brockman S, Bruce D, Power B. The syndromal validity and nosological position of apathy in Parkinson's disease. Mov Disord. 2009; 24(8): 1211-1216

[28] Aarsland D, Brønnick K, Alves G, Tysnes OB, Pedersen KF, Ehrt U, Larsen JP. The spectrum of neuropsychiatric symptoms in patients with early untreated Parkinson's disease. J Neurol Neurosurg Psychiatry. 2009; 80(8): 928-930.

[29] Reijnders JS, Scholtissen B, Weber WE, Aalten P, Verhey FR, Leentjens AF. Neuroanatomical correlates of apathy in Parkinson's disease: A magnetic resonance imaging study using voxel-based morphometry. Mov Disord. 2010; 25(14): 2318-2325.

[30] Leiknes I, Tysnes OB, Aarsland D, Larsen JP. Caregiver distress associated with neuropsychiatric problems in patients with early Parkinson's disease: the Norwegian ParkWest study. Acta Neurol Scand. 2010; 122(6): 418-424.

[31] Drijgers RL, Dujardin K, Reijnders JS, Defebvre L, Leentjens AF. Validation of diagnostic criteria for apathy in Parkinson's disease. Parkinsonism Relat Disord. 2010; 16(10): 656-660.

[32] Pedersen KF, Alves G, Brønnick K, Aarsland D, Tysnes OB, Larsen JP. Apathy in drug-naïve patients with incident Parkinson's disease: the Norwegian ParkWest study. J Neurol. 2010; 257(2): 217-223.

[33] Kirsch-Darrow L, Marsiske M, Okun MS, Bauer R, Bowers D. Apathy and depression: separate factors in Parkinson's disease. J Int Neuropsychol Soc. 2011; 17(6): 1058-1066.

[34] Varanese S, Perfetti B, Ghilardi MF, Di Rocco A. Apathy, but not depression, reflects inefficient cognitive strategies in Parkinson's disease. PLoS One. 2011; 6(3): e17846.

[35] Leroi I, Harbishettar V, Andrews M, McDonald K, Byrne EJ, Burns A. Carer burden in apathy and impulse control disorders in Parkinson's disease. Int J Geriatr Psychiatry. 2012; 27(2): 160-166.

[36] Leroi I, Andrews M, McDonald K, Harbishettar V, Elliott R, Byrne EJ, Burns A. Apathy and impulse control disorders in Parkinson's disease: a direct comparison. Parkinsonism Relat Disord. 2012; 18(2): 198-203.

[37] Ziropadja Lj, Stefanova E, Petrovic M, Stojkovic T, Kostic VS. Apathy and depression in Parkinson's disease: the Belgrade PD study report. Parkinsonism Relat Disord. 2012; 18(4): 339-342.

[38] Benito-León J, Cubo E, Coronell C; ANIMO Study Group. Impact of apathy on health-related quality of life in recently diagnosed Parkinson's disease: the ANIMO study. Mov Disord. 2012; 27(2): 211-218.

[39] Cubo E, Benito-León J, Coronell C, Armesto D, ANIMO Study Group. Clinical correlates of apathy in patients recently diagnosed with Parkinson's disease: the ANIMO study. Neuroepidemiology. 2012; 38(1): 48-55. 
[40] Starkstein SE, Petracca G, Chemerinski E, Kremer J. Syndromic validity of apathy in Alzheimer's disease. Am J Psychiatry. $2001 ; 158(6)$ : 872-877.

[41] Starkstein SE, Jorge R, Mizrahi R, Robinson RG. A prospective longitudinal study of apathy in Alzheimer's disease. J Neurol Neurosurg Psychiatry 2006; 77(1): 8-11.

[42] Robert P, Onyike CU, Leentjens AF, Dujardin K, Aalten P, Starkstein S, Verhey FR, Yessavage J, Clement JP, Drapier D, Bayle F, Benoit M, Boyer P, Lorca PM, Thibaut F, Gauthier S, Grossberg G, Vellas B, Byrne J. Proposed diagnostic criteria for apathy in Alzheimer's disease and other neuropsychiatric disorders. Eur Psychiatry. 2009; 24(2): 98-104.

[43] Starkstein SE, Leentjens AF. The nosological position of apathy in clinical practice. J Neurol Neurosurg Psychiatry. 2008; 79(10): 1088-1092.

[44] Marin RS, Biedrzycki RC, Firinciogullari S. Reliability and validity of the Apathy Evaluation Scale. Psychiatry Res. 1991; 38(2): 143-62.

[45] Starkstein SE. Apathy and withdrawal. Int Psychogeriatr 2000; 12(Suppl 1): 135-138.

[46] Leentjens AF, Dujardin K, Marsh L, Martinez-Martin P, Richard IH, Starkstein SE, Weintraub D, Sampaio C, Poewe W, Rascol O, Stebbins GT, Goetz CG. Apathy and anhedonia rating scales in Parkinson's disease: critique and recommendations. Mov Disord. 2008; 23(14): 2004-2014.

[47] Sockeel P, Dujardin K, Devos D, Denève C, Destée A, Defebvre L. The Lille apathy rating scale (LARS), a new instrument for detecting and quantifying apathy: validation in Parkinson's disease. J Neurol Neurosurg Psychiatry. 2006; 77(5): 579-584.

[48] Zahodne LB, Young S, Kirsch-Darrow L, Nisenzon A, Fernandez HH, Okun MS, Bowers D. Examination of the Lille Apathy Rating Scale in Parkinson disease. Mov Disord. 2009; 24(5): 677-683.

[49] Dujardin K, Sockeel P, Delliaux M, Destée A, Defebvre L. The Lille Apathy Rating Scale: validation of a caregiver-based version. Mov Disord. 2008; 23(6): 845-849.

[50] Grossi D, Santangelo G, Barbarulo AM, Vitale C, Castaldo G, Proto MG, Siano P, Barone P, Trojano L. Apathy and related Executive Syndromes in Dementia associated with Parkinson's Disease and in Alzheimer's Disease. Behav Neurol; In press.

[51] Schrag A, Barone P, Brown RG, Leentjens AF, McDonald WM, Starkstein S, Weintraub D, Poewe W, Rascol O, Sampaio C, Stebbins GT, Goetz CG. Depression rating scales in Parkinson's disease: critique and recommendations. Mov Disord. 2007; 22(8): 1077-1092.

[52] Santangelo G, Vitale C, Trojano L, Longo K, Cozzolino A, Grossi D, Barone P. Relationship between depression and cognitive dysfunctions in Parkinson's disease without dementia. J Neurol. 2009; 256(4): 632-638

[53] Santangelo G, Morgante L, Savica R, Marconi R, Grasso L, Antonini A, De Gaspari D, Ottaviani D, Tiple D, Simoni L, Barone P, PRIAMO Study Group. Anhedonia and cognitive impairment in Parkinson's disease: Italian validation of the Snaith-Hamilton Pleasure Scale and its application in the clinical routine practice during the PRIAMO study. Parkinsonism Relat Disord. 2009; 15(8): 576-581.

[54] Zahodne LB, Marsiske M, Okun MS, Rodriguez RL, Malaty I, Bowers D. Mood and motor trajectories in Parkinson's disease: multivariate latent growth curve modeling. Neuropsychology. 2012; 26(1): 71-80.
[55] Dujardin K, Sockeel P, Delliaux M, Destée A, Defebvre L. Apathy may herald cognitive decline and dementia in Parkinson's disease. Mov Disord. 2009; 24(16): 2391-2397.

[56] Ready RE, Friedman J, Grace J, Fernandez H. Testosterone deficiency and apathy in Parkinson's disease: a pilot study. J Neurol Neurosurg Psychiatry. 2004; 75(9): 1323-1326.

[57] Kehagia AA, Barker RA, Robbins TW. Neuropsychological and clinical heterogeneity of cognitive impairment and dementia in patients with Parkinson's disease. Lancet Neurol. 2010; 9(12): 1200-1213.

[58] Figiel G, Sadowsky C. A systematic review of the effectiveness of rivastigmine for the treatment of behavioral disturbances in dementia and other neurological disorders. Curr Med Res Opin. 2008 Jan; 24(1): 157-66.

[59] Wynn ZJ, Cummings JL. Cholinesterase inhibitor therapies and neuropsychiatric manifestations of Alzheimer's disease. Dement Geriatr Cogn Disord. 2004; 17(1-2): 100-8.

[60] Zgaljardic DJ, Borod JC, Foldi NS, Rocco M, Mattis PJ, Gordon MF, Feigin AS, Eidelberg D. Relationship between selfreported apathy and executive dysfunction in nondemented patients with Parkinson disease. Cogn Behav Neurol. 2007; 20(3): 184-192.

[61] Leroi I, Ahearn DJ, Andrews M, McDonald KR, Byrne EJ, Burns A. Behavioural disorders, disability and quality of life in Parkinson's disease. Age Ageing. 2011; 40(5): 614-621.

[62] Barone P, Antonini A, Colosimo C, Marconi R, Morgante L, Avarello TP, Bottacchi E, Cannas A, Ceravolo G, Ceravolo R, Cicarelli G, Gaglio RM, Giglia RM, Iemolo F, Manfredi M, Meco G, Nicoletti A, Pederzoli M, Petrone A, Pisani A, Pontieri FE, Quatrale R, Ramat S, Scala R, Volpe G, Zappulla S, Bentivoglio AR, Stocchi F, Trianni G, Dotto PD, PRIAMO study group. The PRIAMO study: A multicenter assessment of nonmotor symptoms and their impact on quality of life in Parkinson's disease. Mov Disord. 2009; 24(11): 1641-1649.

63] McKinlay A, Grace RC, Dalrymple-Alford JC, Anderson T, Fink J, Roger D. A profile of neuropsychiatric problems and their relationship to quality of life for Parkinson's disease patients without dementia. Parkinsonism Relat Disord. 2008; 14(1): 37-42.

[64] Zarit SH, ToddPA, ZaritJM. Subjective burden of husbands and wives as caregivers: a longitudinal study. Gerontologist. 1986; 26: 260-266.

[65] Skidmore FM, Yang M, Baxter L, von Deneen K, Collingwood J, He G, Tandon R, Korenkevych D, Savenkov A, Heilman KM, Gold M, Liu Y. Apathy, depression, and motor symptoms have distinct and separable resting activity patterns in idiopathic Parkinson disease. Neuroimage. 2011 Jul 14; In press.

[66] Remy P, Doder M, Lees A, Turjanski N, Brooks D. Depressionin Parkinson's disease: loss of dopamine and noradrenaline innervations in the limbic system. Brain 2005; 128(Part 6): 1314-1322.

[67] Le Jeune F, Drapier D, Bourguignon A, Peron J, Mesbah H, Drapier S, et al. Subthalamic nucleus stimulation in Parkinson disease induces apathy: a PET study. Neurology 2009; 73(21): 1746-1751.

[68] Robert G, Le Jeune F, Lozachmeur C, Drapier S, Dondaine T, Péron J, Travers D, Sauleau P, Millet B, Vérin M, Drapier D. Apathy in patients with Parkinson disease without dementia or depression: A PET study. Neurology. 2012; 79 (11): 11551160.

[69] Chase TN. Apathy in neuropsychiatric disease: diagnosis, pathophysiology, and treatment. Neurotox Res. 2011; 19(2): 266-278. 
[70] Borek LL, Chou KL, Friedman JH. Management of the behavioral aspects of Parkinson's disease. Expert Rev Neurother. 2007; 7(6): 711-725.

[71] Czernecki V, Schipbach M, Yaici S, Levy R, Bardinet E, Yelnik J, Dubois B, Agid Y. Apathy following subthalamic stimulation in Parkinson disease: a dopamine responsive symptom. Mov Disord. 2008; 23(7): 964-969.

[72] Ferreri F, Agbokou C, Gauthier S. Recognition and management of neuropsychiatric complications in Parkinson's disease. CMAJ. 2006; 175(12): 1545-1552.

[73] Czernecki V, Pillon B, Houeto JL, Pochon JB, Levy R, Dubois B. Motivation, reward, and Parkinson's disease: influence of dopatherapy. Neuropsychologia 2002; 40(13): 2257-2267.

[74] Leentjens AF, Koester J, Fruh B, Shephard DT, Barone P, Houben JJ. The effect of pramipexole on mood and motivational symptoms in Parkinson's disease: a meta-analysis of placebo-controlled studies. Clin Ther 2009; 31(3): 89-98.

[75] Lhommée E, Klinger H, Thobois S, Schmitt E, Ardouin C, Bichon A, Kistner A, Fraix V, Xie J, Aya Kombo M, Chabardès S, Seigneuret E, Benabid AL, Mertens P, Polo G, Carnicella S, Quesada JL, Bosson JL, Broussolle E, Pollak P, Krack P. Subthalamic stimulation in Parkinson's disease: restoring the balance of motivated behaviours. Brain. 2012 May; 135(Pt 5): 1463-77.
[76] Thobois S, Ardouin C, Lhommée E, Klinger H, Lagrange C, Xie J, Fraix V, Coelho Braga MC, Hassani R, Kistner A, Juphard A, Seigneuret E, Chabardes S, Mertens P, Polo G, Reilhac A, Costes N, LeBars D, Savasta M, Tremblay L, Quesada JL, Bosson JL, Benabid AL, Broussolle E, Pollak P, Krack P. Non-motor dopamine withdrawal syndrome after surgery for Parkinson's disease: predictors and underlying mesolimbic denervation. Brain. 2010 Apr; 133(Pt 4): 111127.

[77] Starkstein SE. Apathy in Parkinson's disease: diagnostic and etiological dilemmas. Mov Disord. 2012; 27(2): 174-178.

[78] Starkstein SE, Brockman S. Apathy and Parkinson's disease. Curr Treat Options Neurol. 2011; 13(3): 267-273.

[79] Weintraub D, Mavandadi S, Mamikonyan E, Siderowf AD, Duda JE, Hurtig HI, Colcher A, Horn SS, Nazem S, Ten Have TR, Stern MB. Atomoxetine for depression and other neuropsychiatric symptoms in Parkinson disease. Neurology. 2010; 75(5): 448-455.

[80] Levin OS. Coaxil (tianeptine) in the treatment of depression in Parkinson's disease. Neurosci Behav Physiol. 2007; 37(4): 419-424.

[81] Chatterjee A, Fahn S. Methylphenidate treats apathy in Parkinson's disease. J Neuropsychiatry Clin Neurosci 2002; 14(4): 461-462. 


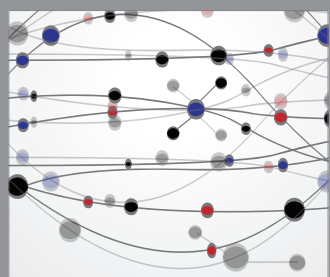

The Scientific World Journal
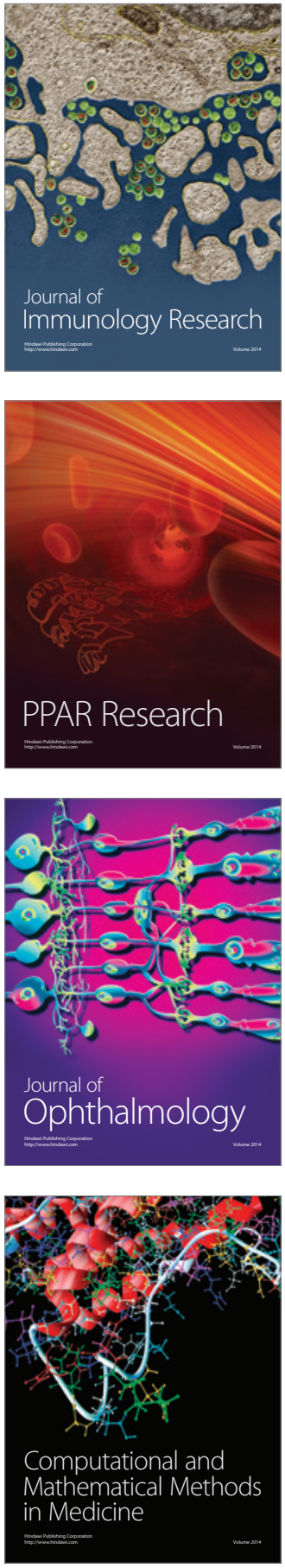

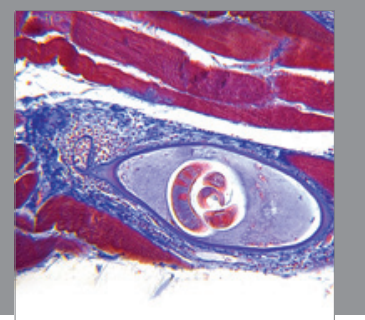

Gastroenterology

Research and Practice
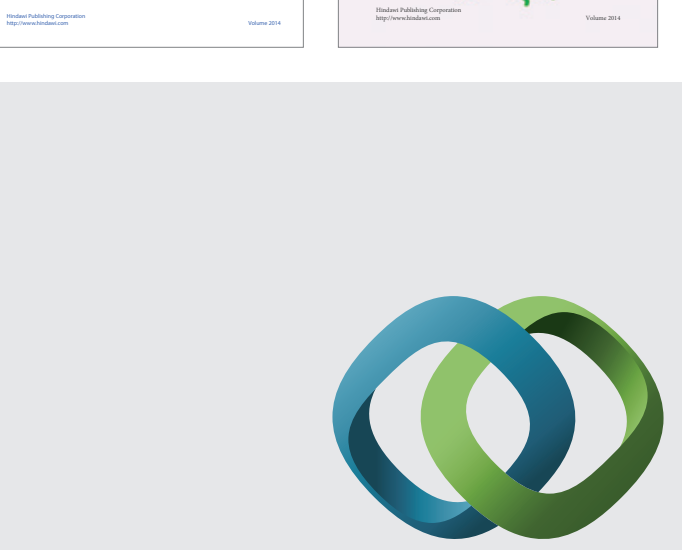

\section{Hindawi}

Submit your manuscripts at

http://www.hindawi.com
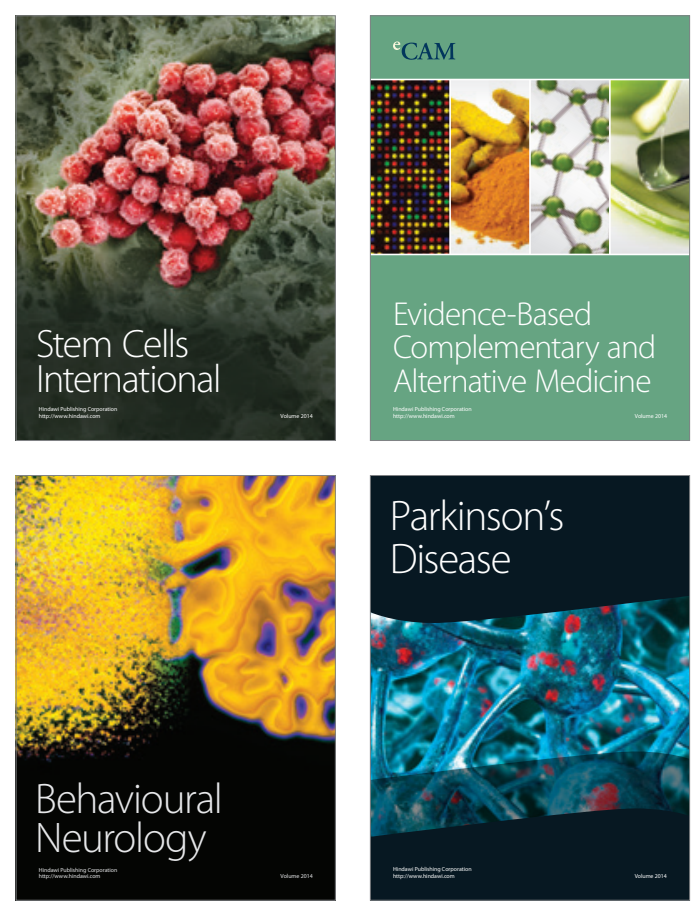

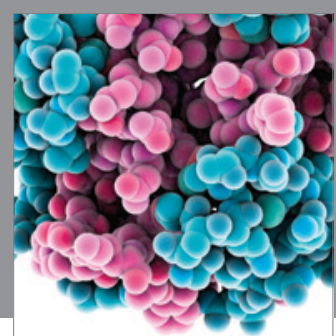

Journal of
Diabetes Research

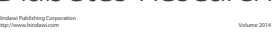

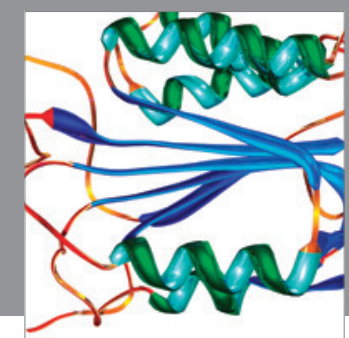

Disease Markers
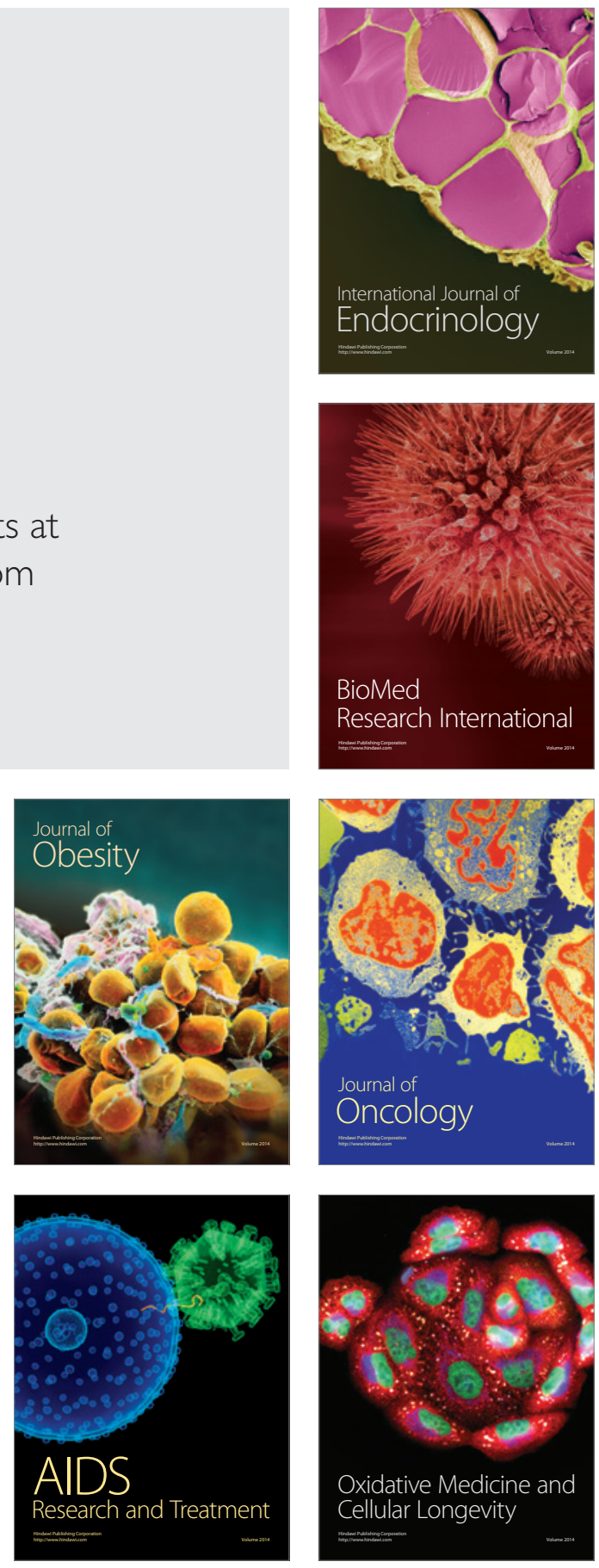